Review Article

\title{
Helping children build inner-driven self-esteem by turning praise into encouragement
}

\begin{abstract}
In order to test the efficacy of praise for boosting self-esteem and strengthening motivation for mastering difficult task, scientists have looked into various types of positive feedback given to children and analysed their effects and possible developmental outcomes they may produce. Praise given for personality-traits is conducive to fear of future performance and valuing oneself according to the achievements attained. Praise focused on the effort is felt as a support to the child to stay in the activity and work hard to achieve their best. On the contrary, a feedback provided in a form of encouragement helps the child meeting their relational needs and supports their autonomy, which raises internally driven self-esteem.
\end{abstract}

Keywords: praise, encouragement, self-esteem, motivation, communication, resilience
Volume I Issue 6 - 2014

\section{Mina Dordevic}

Psychologist, Croatia

\author{
Correspondence: Mina Dordevic, Psychological Association \\ for Research, Education and Counselling "Research Me", \\ Buliceva 10, Zagreb, Croatia, Tel 386000000000 , \\ Emailmina_djordjevic@yahoo.co.uk
}

Received: October 29, 2014 | Published: November 13, 2014

\section{Introduction}

\section{Communication awareness and meeting relational needs}

People are born in a relationships and need them throughout their lives in order to meet their basic needs such as having a sense of belonging, feel secure in a relationship, being recognized and positively validated, influencing other people, forming self-identity etc. ${ }^{1}$ Relatively stable pattern of how people relate to others and try to meet their relational needs largely replicates the character of early relationships with significant others, primarily attachment figures. Therefore, awareness of how interpersonal interactions can influence and shape personality is of crucial importance for parents, teachers and all educators concerned with the children's development and well-being.

The fundamental elements of the intricate workings of human interactions are communication transactions or messages people try to convey to one another. Positive feedback to the children intuitively seems as an utterly positive and unquestionable aspect of communication, though the way it is to be formulated has stirred some controversy over the last decades among parents and caregivers alike. The most conventional type of positive feedback is praise. Praise is ingrained in our society and widely used as a way of either modifying or reinforcing children's behaviour. As transactional analysis theory vividly describes, expressions often heard throughout childhood, such as "Good boy!" or "You are so smart!", as much as more negative ones, are recorded in people's minds as if on the recording tapes. They represent interjected pre-judged and pre-programmed statements which are automatically activated and expressed in similar situations in adult life. ${ }^{2}$ Over the past several decades, researchers have tried to comprehend the meaning that such expressions may carry as well as their implications for children's development and psychological wellbeing.

It is important to mention this distinction in order to talk about the shift of libido during pregnancy. First of all, a woman has to use her object libido to get pregnant that is, she has to reach another object to conceive a baby. Pregnancy is a state that could be understood as a very narcissistic one where many women can feel ultimately "complete". The feeling of having a human being inside her womb can be very powerful, people will take care of her, sexual experience is often limited and an internal journey takes place as libido is taken inwardly in order to preserve a balanced state that reassures the process.

Today the association between excessive praise and its harmful effects to internally driven self-esteem, intrinsic motivation and even performance is well documented. ${ }^{3,4}$ Nevertheless, more perceptive statements of encouragement which mirror the intrinsic feelings of a child and communicate to the child that they are seen, accepted as are and believed in, strengthen the child's autonomy and positive feeling about themselves. The author does not intend here to provide an extensive review of the findings in the field, but rather a summary and discussion of the literature that highlights the beneficial effects of descriptive and empathetic feedback compared to simple praise statements.

\section{Discussion}

\section{Effects of communicating praise}

Praise is positive, well intentioned statement, often deliberately given to children to boost their self-esteem. In order to test efficacy of such endeavour, the researchers have distinguished praise given for ability or personality trait (e.g. "You are so intelligent!" or "You are such a good boy!") from praise given for the process of engaging in an activity (e.g. "You are working hard!").

The research has shown that person-praise creates the idea that personality characteristics are stable and not particularly susceptible to change. The implication of such praise for potential failure ist hat the children who received a lot of person-praise (e.g. "Bravo, how clever/witty you are!"), attribute lack of success in a certain activity to their innate, fixed characteristics or conceived inadequacies. Equally, they tend to measure their abilities by the level of achievement in a certain activity, which makes them fully focused on the outcome while neglecting emotions attached to the process of performance. ${ }^{5}$ Such attitude contributes to the fear of meeting high standards and feeling of shame in a case of failure, thus rendering a child more emotionally vulnerable ${ }^{6}$. This developmental outcome further steers children's behaviour towards avoiding challenging tasks and thus losing an opportunity to learn, less intrinsically enjoy the play or learning process and may even prompts them to cheat. ${ }^{5,7}$

In addition, praise for an easy task may well be explained by children as lack of faith in their abilities or actual low level of abilities and thus 
negatively impact their self-worth. ${ }^{4}$ Moreover, pairing person-praise with social comparison ("You are the best helper/artist/speaker in the class!"), makes the children inclined to assess their worth against how successful they are in regard with their peers. The notion of having failed due to irreparable flaws which others do not possess, elicits the feelings of frustration and helplessness. If perpetuated over time and across various situations, such states may become pretty stable characteristics interfering with well-being in adulthood.

Gunderson et al., ${ }^{7}$ ideas of the innate human characteristics emerge as early as in preschool years and apply equally to both cognitive as well as socio-moral attributes. If a child is made believe that goodness is a fixed trait then they would feel more righteous if an interpersonal conflict occurs and less likely to put an effort to constructively solve the dispute. Such beliefs are developed if a child gets frequently labelled as "good", "nice", "sensitive", "neat" etc. An attribution is to be obeyed "implicitly" and is, in a sense, equivalent to an instruction. Assigning attributes in a superficial manner without endeavouring to really understand and mirror child's true feeling and drives in a specific situation may result in developing characteristics which are not inherent or authentic to the child.

Furthermore, praise statements experienced as controlling ("Excellent, you should keep up with the good work!") may haved etrimental effect on intrinsic motivation unlike more informational feedback, as the former is felt as putting additional pressure. ${ }^{9}$ In addition, expressing excessive praise and proud ness in children's success, even when a child does not seem to enjoy the particular activity is, contrary to the common belief, not contributory to the children's motivation but rather a way to turn child's achievement into parent's own story. A child becomes happy for pleasing the parent and starts worrying about receiving the same acceptance in the future. ${ }^{3}$

In classroom setting, praise statements given by teachers have shown to be associated with shorter task persistence, more hesitant speech when answering questions, fewer possible answers to the question and lowered expectation of success for difficult tasks..$^{10}$ On the other hand, process-praise ("Your persistence in such a difficult task is really admirable!") is more focused on the effort and level of commitment a child displays when undertaking an activity. This type of feedback given to a child is more associated with valuing the effort, viewing a challenging situation as an opportunity to learn ${ }^{7}$ and forming more realistic belief that success is attainable.

Nevertheless, a study in which the intrinsic motivation for the task was assessed in three groups of pre-schoolers which received a person-praise (e.g., "You are a great puzzle-solver!"), process praise (e.g.,"You're finding really good ways to do this!") and neutral feedback (e.g., "You finished both puzzles."), respectively, for task performance and subsequently failed in a second task, showed that the greatest benefit for the intrinsic motivation was elicited by the process-praise then person-praise and that the least beneficial was neutral feedback. ${ }^{4}$ Still, the study did not include the encouragement situation (e.g. "I knew you would finish both puzzles, and look how quickly!") and although, contrary to earlier mentioned findings, it sheds some positive light on praise-formulations it is not informative of its effects in comparison with encouragement.

\section{Effects of communicating encouragement}

Taking classical verbal reinforcement such as praise one step further and turning it into encouragement, which is less of a value judgement and more of a description of the processes that arise when a child engages in an activity, results in different and more favourable developmental outcomes. ${ }^{10,11}$
When caregivers are attentive about emotions that certain activity elicits in a child and try to reflect those feelings back to the child in order to help them raise awareness or knowledge about the interconnection between their thoughts, behaviours and feelings they are using encouraging messages. Recognizing how pleasing or simulative an activity is for a child and showing emotional tuning rein forces child's intrinsic motivation. ${ }^{10}$ Thus a sentence such as "You seem to be really enjoying your dance class each time!" conveys an impression of child's feelings and is more likely to make the child pursue their activity then a more evaluative feedback as "You are a good dancer!". In a similar fashion, a statement "You are really proud of what you've achieved! I suggest we go and celebrate it now!"offers celebration of child's feelings instead of reward for child's success. To the contrary, a statement "This is a great picture; you've made your Dad really proud! Now I'll buy you some new tools that you wanted!" focuses on pleasing parent and therefore earning a reward.

Acknowledgment of the engagement and effort a child puts in a freely chosen activitystrengthens the child's autonomous functioning as it is a sign of accepting children as they are ${ }^{3}$. This is illustrated in a message such as" You seem very committed to doing your best here!" or "You've been working hard and you have achieved your goal!"or "You have made a plan and have stuck to it!" Furthermore, encouragement induces children to compare progress they are making with their earlier level of attainment in a specific activity without having to divert their attention to the achievement of others. ${ }^{8}$ Social comparison may produce unhelpful anxiety and takes up part of the child's capacities which could have been better used if devoted to enjoying the process itself. A general statement like "Look at the progress you've made!" or even more specific feedback (e.g. "Each time you make it, your wood block castle gets more and more elaborated!") draws child's attention to their internal process and developments ensued their efrom.

Additionally, encouragement shows caregiver's faith ${ }^{3}$ into child's capabilities thus enablingthemto internalize that confidence and generalize it across various traits and situations. Examples are: "I am confident you will figure it out!" or "You know how to do it your own way!" Similarly, encouragement messages convey appreciations for child's contributions such as: "I appreciate your help very much!", or "You've made me look at it from different perspective and that was a great help!"

However, the author concludes that encouragement received during childhood predisposes children to depend less on the evaluative judgements expressed by others, usually authority figures such as parents, teachers or supervisors and managers, later in life, and give more utterance to the internal messages .In line with the Steiner's tape-recorder metaphor, encouragement frequently received in childhood makes this inner voice more positively charged thus rendering a person more inclined to view stressful situations as temporary obstacles or challenges. Thus perseverance and drive for improvement is not motivated by the fear of failure or criticism but rather by feeling of pleasure for achieving one's internal standards.

A frame of mind structured in such a manner allows for internally driven motivation to guide behaviour and for creativity to thrive, and moreover, it strengthens confidence into successful coping with any type of adversities what builds emotional resilience and self-esteem. ${ }^{3}$

\section{Sources of unambiguity}

Finally, it is important to mention that children interpretations of feedback messages are influenced by various moderating variables (e.g. gender, age, contextual variable such as presence of another 
child, quality of relationship with the adult etc.) and mediating variables (e.g. the psychological process such as perception of an adult as controlling and manipulative or helpful and sincere, etc. ${ }^{4}$ making thus difficult to draw unambiguous conclusions of the potential effects of such statements. Also, when examining the effects of praise, it is important for research studies to include encouragement as an experimental situation in addition to type of praise, lack of praise or neutral feedback in order to allow for more elaborate examination of communication effects.

With regard to direction for future research, it would be invaluable to assess the effects of encouragement versus both type of praise statements on preschool children, while taking into consideration the emotional tone accompanying each statement, and examine their potentially long-term effects on the development of traits such as autonomy and self-worth.

\section{Conclusion}

Teaching children to heavily rely on the compliments, especially for their innate characteristics and task outcomes, makes children attribute failures to personal deficiencies which interfere with psychological well-being. However, praise focused on the effort and improvement is more associated with persistence in a task as the engagement in the process is being reinforced. Nonetheless, excessive praise makes children value their own worth according how much praise they receive from others and creates sort of praise contingent self-esteem.

On the other hand, encouragement which is a descriptive message encompassing child's feelings about an activity, their level of engagement, faith in their capacities and appreciation of their contributions stems from healthy relational dynamics between a child and a caregiver and as such cultivates a strong sense of self-worth and nourishes the child's feeling of being ok.

\section{Acknowledgments}

None.

\section{Conflicts of interest}

Author declares there are no conflicts of interest.

\section{Funding}

None.

\section{References}

1. Erskine, Richard G. Attachment, Relational-Needs and Psychotherapeutic Presence. International Integrative Psychotherapy Association Conference. Vichy, France. 2011

2. Steiner C. A Compilation of Core Concepts. Compiled by the ITAA Development Committee Task Force on Transactional Analysis Core Concepts. 2000.

3. Landreth GL, Bratton SC.Child Parent Relationship Therapy (CPRT) Abingdon, Oxon: Routledge. 2005.

4. Henderlong J, Lepper MR. The effects of praise on children's intrinsic motivation: A review and synthesis. Psycho Bull. 2002;128(5):774-795.

5. Mueller CM, Dweck CS. Praise for intelligence can undermine children's motivation and performance. J Pers Soc Psychol. 1998;75(1):33-52.

6. Brummelman E, Thomaes S, Overbeek G, et al. On feeding those hungry for praise: Person praise backfires in children with low self-esteem. $J$ Exp Psychol Gen. 2013;143(1):9-14.

7. Gunderson EA, Gripshover SJ, Romero C, et al. Parent praise to 1-to 3 -year-olds predicts children's motivational frameworks 5 years later. Child Dev. 2013;84(5):1526-1541.

8. Steiner C. Scripts people live; transactional analysis of life scripts. Grove Press, New York, USA. 1974.

9. Deci EL, Koestner R, Ryan RM. A meta-analytic review of experiments examining the effects of extrinsic rewards on intrinsic motivation. Psychol Bull. 1999;125(6):627-668.

10. Kelly FD, Daniels JG. The effects of praise versus encouragement on children's perception of teachers. Individual Psychology: The Journal of Adlerian Theory. 1997;53(3):331.

11. Carns MR, Carns AW. A review of the professional literature concerning the consistency of the definition and application of Adlerian encouragement. Journal of Individual Psychology. 1998;54(1):72. 